This item was submitted to Loughborough's Research Repository by the author.

Items in Figshare are protected by copyright, with all rights reserved, unless otherwise indicated.

\title{
Tracing the tensions surrounding understandings of agency and knowledge in technology design
}

\section{PLEASE CITE THE PUBLISHED VERSION}

http://designmanagementacademy.com/dma2017/

\section{PUBLISHER}

Design Management Academy

\section{VERSION}

AM (Accepted Manuscript)

\section{PUBLISHER STATEMENT}

This work is made available according to the conditions of the Creative Commons Attribution-NonCommercial 4.0 International (CC BY-NC 4.0) licence. Full details of this licence are available at: http://creativecommons.org/licenses/by-nc/4.0/

\section{LICENCE}

CC BY-NC 4.0

\section{REPOSITORY RECORD}

Neubauer, Ruth, Erik Bohemia, and Kerry Harman. 2019. "Tracing the Tensions Surrounding Understandings of Agency and Knowledge in Technology Design”. figshare. https://hdl.handle.net/2134/24921. 


\title{
Tracing the tensions surrounding understandings of agency and knowledge in technology design
}

\author{
NEUBAUER Ruth ${ }^{\mathrm{a}^{*}}$, BOHEMIA Erik $^{\mathrm{a}}$ and HARMAN Kerry ${ }^{\mathrm{b}}$ \\ ${ }^{a}$ Loughborough University London \\ ${ }^{b}$ Birkbeck, University of London \\ * Corresponding author e-mail: r.neubauer@lboro.ac.uk \\ Paper number: 70
}

The literature suggests that prevailing understandings of the makeup of design knowledge and agency in producing design knowledge in technology is not helpful for design processes and its practitioners.

Tensions arise within processes of designing, when design knowledge is understood as objective, whilst subjectivity is experienced in the research methods employed. In the same time, knowledge production is pursued in an individualist manner, where the situated nature of knowing as an interplay of factors, likely reaching beyond personal traits and human intention, is not acknowledged.

In this way, design processes are currently working against their inherent potential with likely effects on designers and subsequently design outcomes. The arising tensions cause issues for practitioners, who are stuck in between an objectivity demand and experienced subjectivity, without an alternative conception of their work.

Practice-oriented conceptualisations of social dynamics, how things are, and come to be, as well as existing research in consumption practices and sustainable design, have shown that agency and knowing conceptualised as emerging from practice might reconcile this tension. It is therefore that we argue for a reconceptualization of the makeup of knowledge and agency in knowledge production, so that these advancements in conceptualising practices can be of service to the technology design discipline.

human-computer interaction, user experience design, practice theory, materiality 


\section{Review of paradigms}

Agency and structure are fundamental subjects in the study of the make up of social life. They are about the relationship between individuals and the 'social' in which they participate. To what extent individuals have capacity to act amid the constraints in this social process, is the subject of much debate between various strands of thinking (Johnson, 2000).

Four paradigmatic forces can be identified within existing efforts of describing design. On the one hand, there are two opposing ends of understanding design knowledge as objective (the results of rational thinking) and understanding design knowledge as subjective (the result of practical doing). On the other hand, there are two competing views of the production of design knowledge via individual skill versus design knowledge emerging from social participation. The paradigmatic force field could be visualised as four arrows pointing in four different directions: objectivist versus subjectivist, and individualist versus participative. Neither of the following accounts speak explicitly about these opposing forces or categorise accordingly; the visualisation of the four pulling forces is a mere support structure for making sense of the various accounts and categorisations within this space (see Figure 1).

Fallman (2003) speaks of three distinctions of how design is understood today: 1) The conservative, 2) the romantic, and 3) the pragmatic approach. He sees the conservative approach to design as a scientific and logic-oriented process of problem solving (see Simon, 1996). In this "process-oriented" account, methods and structure build the core, and the designer takes the position of a natural scientist. Fallman describes the designer here as someone who is able to follow plans and prescribed steps; this understanding of design "disembodies" the designer in the process. It could be interpreted that the designer's cognitive skills are a scientific instrument here.

Fallman places the conservative approach in juxtaposition to the romantic approach, which places the designer in the centre of the design process, whereby the designer possesses "almost magical abilities of creation" (p. 226). Here, the designer utilises gifts such as intuition, imagination and creativity, and is not able to express in words the process of design. Fallman assigns the origins of this type of understanding design to art, and the individualist thinking inherent to romanticism. Fisher (1997) describes this "romantic" stereotype similarly. He even sees it as the prevailing understanding of design, and describes the conflicts that arise for designers in the light of this understanding, which starkly contrasts with every day work practices. Fisher juxtaposed the romantic approach with logical thinking, like Fallman does, but contrasts both categories mainly with the idea that design skills are a situated way of understanding, rather than a given talent. Fallman (2003) goes on to describe a third, the pragmatic, approach.

The pragmatic approach makes use of what materials and resources are available. In the description, Fallman references Schön (1983), with his account of a tacit, intuitive, and reflective knowing-in-action. Also Fisher (1997) speaks of a pragmatic approach, whereby he means a dissolution of the Cartesian subject - object dichotomy. Both mean to describe that in this understanding, designing is not an individual skill but a way of situated and participative knowledge production. Similarly, Wright, Blythe, and McCarthy (2006), call for the pragmatist approach as an alternative to the prevalent "design-as-engineering" and "design-as-craft" approaches. They follow the philosophy of Dewey in proposing that 
knowledge is dependent on the "technology, circumstances, situations, and actions from which it was constructed" (McCarthy \& Wright, 2004, p. 17). A pragmatist understanding of design relies on the participative notion of situated knowledge production, and a resolving of subject-object dichotomies. Caroll (1997) sees an actual transition happening from a "cognitive" approach towards a more "social and contextual" approach.

Accordingly, such developments can be observed in management-oriented literature of product design. In, what could be described as a lose group of methodologies around, Lean and Agile ${ }^{1}$, design processes are appropriated and used by multi-disciplinary teams. These industry-led methodologies do neither relate to the 'romantic' approach, as designers often do not even exist in these teams, nor do they fit with the 'conservative / scientific' approach which takes an abstract stance to design. They fit in their emphasis of situated knowledge production in self-organised teams well with both Fallman's and Fisher's description of the 'pragmatic' approach. They, however, do not explicitly crossreference anti-Cartesian or pragmatic ideas, or indeed reference each other very much (Mueller \& Thoring, 2012).

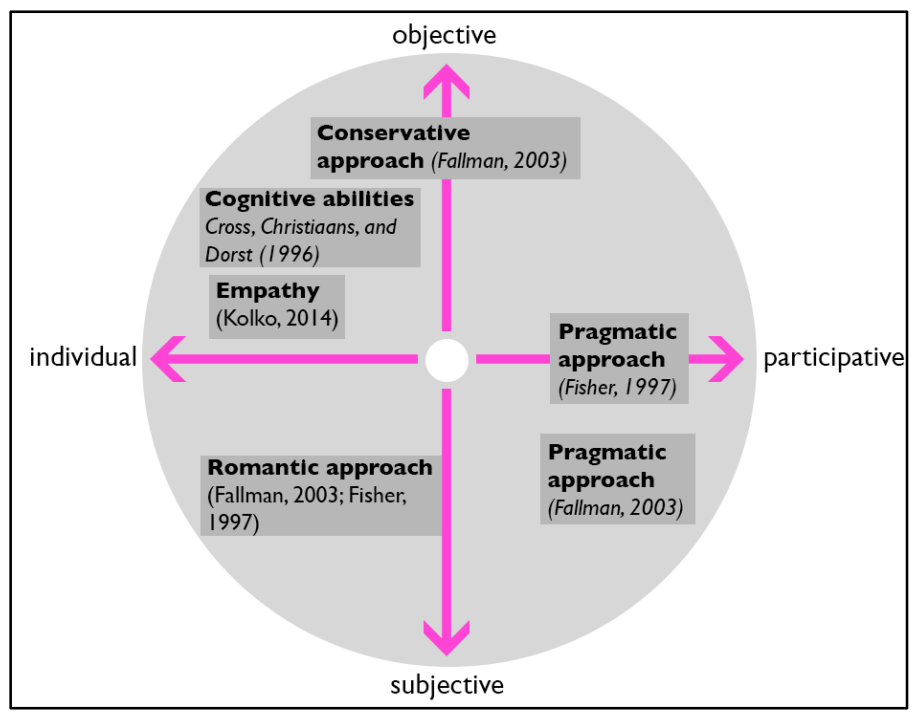

Figure 1 Paradigmatic forces in design theories

Questions of skills and mastery, hinting on specialist individual abilities outside of the rational, have accompanied design literature for a long time. They might be counterintuitive to perceptions of the design process as a scientific instrument (and designers as its extensions), they nevertheless appear in various accounts. Dreyfuss (1955) speaks of the designer as "qualified by experience, observation and research to suggest in advance what a product should look like. As nearly as anyone can, he has mastered what might be called the science of appearance" (p. 65). Cross, Christiaans, and Dorst (1996) celebrate design skills as the "highest cognitive abilities of human beings, including creativity, synthesis and problem solving [where] the most able designers clearly exercise

1 namely Agile software development (Beck et al., 2001), Lean Startup (Ries, 2011), Lean UX (Gothelf \& Seiden, 2013), and Design Sprint (Knapp, Zeratsky, \& Kowitz, 2016) 
exceptional levels of ability" (p. 1). Elsewhere Cross (1982) ascribes "self-confidence" to designers, as a required personal attribute in the face of dealing with wicked problems ( $p$. 224). And in a more recent publishing, Kolko (2014) speaks of empathy as an important trait of design leaders, and quotes Roger Martin: "[design leaders] have the predisposition and the capacity to hold in their heads two opposing ideas at once. [They] creatively solve the tension between those two ideas by generating a new one that contains elements of the others but is superior to both" (Kolko, 2014, p. 22). There is clearly an attributing of exceptional personal traits going on, where designers' abilities are spoken about in individualised ways, even outside the "romantic" approach to design (as categorised by Fallman, 2003; Fisher, 1997). We can observe an ongoing story, where designers' special traits and abilities thread through various accounts of older and newer, more rational and less rational accounts of design. However, we will argue that this conception yields challenges to the design process and its participants.

The above reviewed summaries of understandings of design skills ranged, firstly, from a conservative, scientific, logic-oriented and process-oriented objectivist paradigm, to a romantic, intuitive, magical subjectivist paradigm. Secondly, from a skill and talentoriented individualist paradigm, to a situated, social and reflective participative paradigm. The existing paradigmatic space is seen as problematic in theorising design (Fallman, 2003; Fisher, 1997; Kimbell, 2011; Suchman, 1994; Wright et al., 2006) for a number of different reasons which we are going to cover in the following section.

The issues in design hinted at here are on two levels: 1) Agency (is it individual or participative?); 2) Knowledge (is it objective or subjective?).

\section{How agency and knowledge are understood in technology design}

Human Computer Interaction ( $\mathrm{HCl}$ ), which Caroll (1997) describes as a "science of design", and Wright et al. (2006) as the "design-as-engineering approach", is a domain that celebrates scientific knowing, whereby the process is defined by empirical data gathering. Assuming a "fixed problem statement", designers work methodologically though "proceduralised" steps of research and design, to arrive at an "abstract specification of the solution" (p. 3). These engineering-oriented, technical ways of designing are defined by a systematic process of analysis, synthesis and evaluation (see Jones, 1963) leading into abstract diagram representations. The "boxes-and-arrows" approach to design leads to an externalisation of the "rationality of design work into guidelines" (p. 226), says Fallman (2003), and the role of the designer being deemphasized in this "disembodied design process" (p. 3). The driving force of design, in the engineering approach of designing technology, is ascribed to the rational process, rather than the designer. In the meantime, the designer is conceptualized as a scientific instrument in this process.

However, the role of the designer has changed alongside the developments of $\mathrm{HCl}$. In its beginnings, $\mathrm{HCl}$ practitioners were research-oriented, and informed interaction designers and engineers of their findings which would in turn inform the designs. Zimmerman, Forlizzi, and Evenson (2007) report the frustration of designers who would only be included at the end of a project to make the user interface "pretty". The role of the $\mathrm{HCl}$ researcher and the interaction designer later moved closer together, and $\mathrm{HCl}$ practitioners would often cover both, research and design. In user-centred design (UCD) and user experience design (UX) the research around user needs and the experience of the user is 
central in this design process. There is, however, a clear distinction between the activities of research and the activities of design (Fallman, 2007), and even a "social-technical" gap, implicated by power relations where (social) research is of service to (technical) design (Dourish, 2006).

\section{User-centred design (UCD)}

Even though the integration of the user in the design process has been gradual over the past decades, the user is now understood to be the central point in design. In UCD (see Nielsen, 2000; Norman, 1988) this integration of the user into process-oriented product design brings with it the addition of user requirements, iterative cycles and multidisciplinary teams (Maguire, 2001). Within this process, the designer is responsible for researching user requirements, planning and designing product features accordingly, and iterating designs according to evaluation activities. The designer is supported in making design decisions through research methods such as surveys, interviews, focus groups, personas (see Cooper, 2004), task analysis, heuristic evaluations, and competitor analysis (Maguire, 2001). In older accounts of UCD the user is generally seen as a set of well defined tasks, of which relatively abstract representations suffice (Wright et al., 2006, p. 4). For example, Nielsen (1994) postulates that usability tests need only be conducted with 5 participants in order to find $75 \%$ of usability problems. Here, the user's interactions are treated predictable and controllable "through properties and features of the design" (for a critique of this approach see Wright et al., 2006, p. 6). But with the more recent acknowledgement of use being embedded in a social context, UCD has embraced the use of ethnographic research methods, or specifically, ethnomethodology, as Button (2000) explains the type of research methods typically used in design. Education and industryrelated literature (Garrett, 2011; Kuniavsky, 2003) call it simply "user research". General emphasis is placed on empathy in user research (see for example Young, 2015). The move from $\mathrm{HCl}$ to UX was also a move from lab-based research towards fieldwork (Button, 2000). Discipline-wise this meant a shift from psychology-supported research towards anthropology and sociology-supported research. But with the coming together of anthropological research methods and design, designers are faced with the "distinct style of knowing" that anthropology brings with it (Otto \& Smith, 2013).

\section{The divide between design and use}

This 'supportive function' of social research to design has not gone unchallenged. Suchman (1994) proclaimed that knowledge is not something that can be wrapped up in an object and passed on for use in design and production - that practitioners in the design process are just as entangled in the social activity of producing knowledge. Similarly, Dourish (2006) raises concerns about designers' task of producing ethnographic knowledge and packing it up in the form of a report, as the well known "implications for design" which usually conclude research and pass over to design a catalogue of recommendations and guidelines. Ethnographically acquired knowledge is of limited use as a general representation of users' experience, as it is generated in the situated interplay between researchers and participants. And, he adds, classical ethnography requires the researcher to reflect on their own role in generating this knowledge, which is not taken into consideration in ethnography for design. A second concern raised by Dourish (2006) is around power relations. He says, not only elevates the "implication for design" model designers into the special position of "gatekeepers" for research, it also places both, ethnography, and those who take part in ethnography studies, outside the 
design process. Woolgar (1991) goes so far to suggest, that ethnographic study may be a device, employed by producers to configure users, and exert control to "define, enable and constrain" the user. Mackay, Carne, Beynon-Davies, and Tudhope (2000) respond to that that this goes in a two-way fashion, that designers do certainly configure users, but that designers are also configured through users and through their organisations.

Questions have been raised as to why design and production practice make this distinction between themselves and "the user" (Kuutti, 2001). Hysaalo (2009) explains the separation historically, with the long chain of design, manufacturing, and retail that used to separate design and use in mass production, as well as the distinct "activities" applied in design and use, and a general distribution of expertise and power, and issues of trade secrecy. But Suchman (2002) points out how such separations mask the actual dynamics of designers negotiating a social process, and, for example, are "themselves among the most intensive of technology users" (Suchman, 2002, p. 142).

\section{The divide between 'analysis' and 'synthesis' or 'thinking' and 'doing'}

Gedenryd (1998), in his investigation on designers' ways of working, found out how the supposedly exemplary process of 'problem setting' and 'problem solving' in design 'analysis' of the user and 'synthesis' of findings into designs - which goes back to ancient Greek theories, is not working as expected. He demonstrated how designers' activities were simply not separable into 'analysis' and 'synthesis', but that a "very tight coupling between test and use" within designers' activities made impossible a separation of "problem setting" and "problem solving" (Gedenryd, 1998, p. 86). Fallman (2003) summarises that iterations in UCD, which were meant to overcome the problem of the linearly structured design process, as a way to allow the designer to move 'freely' between the various stages of the process, demonstrate that a distinction between activities cannot be made. He draws on Gedenryd to conclude that the "add-on" of iterations to the structured process is in itself contradictory since it means an active abandonment of the linear process, and instead the embracing of the fact that design activities are "inseparable and intertwined" (Fallman, 2003, p. 229; Gedenryd, 1998). With this, both, Gedenryd and Fallman, make a major statement about the state of $\mathrm{HCl}$. The supposedly objective knowledge production in $\mathrm{HCl}$ is suddenly faced with the subjectivity and "direct involvement" that designing brings with it (Fallman, 2007).

\section{$\mathrm{HCl}^{\prime}$ s conquering of the social context}

The "turn to experience" (Wright et al., 2006) denotes the change that happened when $\mathrm{HCl}^{\prime} \mathrm{s}$ focus shifted from the user interface (UI) and its usability to user experience (UX). It marks the increased interest in the social context of use. The experience users have with products and services has become a perceived competitive advantage for businesses. Reasons for the advent of UX are explained, for example, with the more intertwined relationship between "end user and the organisation creating the experience" (Kuniavsky, 2007, p. 898). User experience design has a largely increased scope, in comparison to traditional usability which concerns largely the ease of use of the user interface. "UX is about everything" (NN group, 2016). Hassenzahl and Tractinsky (2006) define UX as "more than just instrumental needs in a way that acknowledges [the use of technology] as a subjective, situated, complex and dynamic encounter" (p. 95, our emphasis). This 
definition reflects the view of a majority of survey respondents from the UX community (Law, Roto, Hassenzahl, Vermeeren, \& Kort, 2009).

\section{Control over what?}

However, Wright, McCarthy, and Meekison (2003, p. 43) detect an "uneasy silence as to what actually constitutes experience [...] how to account for subjectivity, and whether it is possible to design experience" (p. 43). The all-encompassing and in the same time vague definitions of what user experience comprises, sit uncomfortably with the implied power and control of the design process over the user's experience.

The user experience design process is all about ensuring that no aspect of the user's experience with your product happens without your conscious, explicit intent. This means taking into account every possibility of every action the user is likely to take and under-standing the user's expectations at every step of the way through that process. (Garrett, 2011, p. 19)

It appears that in the era of UX design, some things have changed, and some have remained true to traditional $\mathrm{HCl}$ principles. Design knowledge (experience) is now understood to be subjective of nature. It concerns the encounter of a person with a product in the entirety of its social context, as we can see in the various definitions of UX. However, the process of producing and applying this knowledge is still postulated as an objective process, owned by the individual designer, as we can see for example in the quote from Garrett.

If the too abstract user has caused issues in the past, in terms of absent user subjectivity, in the era of experience new challenges arise with user subjectivity being the object of design.

\section{The object of design and experienced subjectivity}

On the one hand, users' subjectivity has finally found access to design and production in user experience design, in the form of ethnographic and socially oriented research. On the other hand, the designer now scrambles to manage this user involvement - this object of design. Sociological questions are being raised as to why the distinction between designer and user is upheld, how subjectivity and objectivity are perceived in this social knowledge production, and about the designer's own involvement in it. The designer ends up in a situation where he or she is required to create objective knowledge, but through highly subjective means of investigation, and of a highly subjective and situated matter. The demand of rational agency from the designer here, with subjectivity (both their own and others') not accounted for, compounds the knowledge and agency issue in design to a direct contradiction in itself.

It is a tension which one could expect to be felt by practitioners engaged in product design. I am inserting here an extract from Lucy Suchman's paper on the artificiality of the divide of design and use, and her personal experience with expectations around producing these design requirements (or "design implications" as she terms it), and the resulting conflict that arises for her as a practitioner.

A longstanding mutual dissatisfaction between research and product development arises from the failure of technologies and ideas to 'transfer' from one to the other, understood by one side as a failure of development 
to take advantage of the results of research, by the other as a failure of research to address the needs of development.

My own experience of this gap began in the early 1980's in grappling with the question of how an anthropology of technology might be made relevant to the design of machine interfaces. The first proposal was that, as ethnographers, we might mediate relations between designers and users. Increasingly, however, our reluctance to translate our practice directly into design terms was met with frustrations from the design community. [...] Our hesitation to produce such translations led to our characterization as recalcitrant social scientists, unwilling to roll up our sleeves and engage in the real work of design. For a time l at least was confused by this, feeling that to deliver design implications was indeed my responsibility but that I was unable to do so. I dwelled uncomfortably for several years within this gap between my practice and that of my design co-workers, seeing it not as a systemic discontinuity but as a personal shortcoming. (Suchman, 1994, pp. 30-31)

This account of felt experience, in an academic paper, is revealing as to the extent how personally this epistemological problem of objectivity can be felt by practitioners. And it may be not far fetched to assume that the practitioner's experience manifests itself within, and influences in certain ways, the design process and its outcomes.

\section{$\mathrm{HCl}, \mathrm{UX}$ and the problem of objective knowledge and individual agency}

To some extent, it can be derived from the literature that the latest movement in $\mathrm{HCl}$, with increased focus on experience and social context, is exacerbating the existing problem in $\mathrm{HCl}$ - the understanding of knowledge as objective and the understanding of agency as individual. The object of design - experience - is a design object as big and intangible as never before. The unease which practitioners felt before with attempting to create objective knowledge out of situated social interaction between user and machine (Suchman, 1994, pp. 30-31) must be compounded here, where an entire social setting surrounding user and product must fit into this object of design - and be moulded by the designer afterwards. One of the authors of this paper has got many years of experience in $\mathrm{HCl}$. What we can report from these years of working in the field is that there are indeed ongoing debates amongst practitioners reflecting some of these issues which we have derived from the literature. For example, there are numerous blog posts and magazine articles around the question of what UX is (Norman \& Nielsen, 2016; UX Mastery, 2012), and for example around the question whether UX is a process or a verb, to much exasperation of the author - "Okay, so how long to UX it?" (Todish, 2013). There is also a debate whether UX designers design the or for experience (Fredheim, 2016; Olyslager, 2012), indicating a discomfort with the idea that an individual designer would have the power or responsibility to determine the experience a user has with a certain product in their lives. Some publications attempt to tackle the question of the user-designer divide, and indirectly the thinking-doing divide, by bringing users directly into the product development process and by abandoning user research and user representations all together (Gothelf \& Seiden, 2013; Patton, 2014). But perhaps frightening and comforting in the same time is the ongoing suspicion that 'user experience' is only a new buzzword for (the same old) 'usability'. As Scapin, Senach, Trousse, and Pallot (2012) note that "user 
experience" is often used synonymously with "usability". They also note that there is a mix between absolute vagueness what 'experience' means on the one hand, and great efforts to emphasise the difference between 'usability' and 'UX' on the other. This widely practiced public negotiation of what a UX designer's job is (Fredheim, 2016; Norman \& Nielsen, 2016; Olyslager, 2012; Todish, 2013; UX Mastery, 2012), and what it is not - "UX is not UI" (Flowers, 2012), indicates the passion which is behind this topic, and that it could really be interpreted as a search for guidance, which is not provided by the existing academic discourse in the field.

\section{Possible resolution of the knowledge and agency problem}

Despite the growing interest from the $\mathrm{HCl}$ community in user experience (Hassenzahl, 2004), Kuutti and Bannon (2014) have called this quest of focusing on experience in technology design a "tacit, spontaneous, and unsystematic" reaction to what had been going on in the social sciences, in particular related to the "turn to practice". That $\mathrm{HCl}$ was closely wedded to cognitive psychology and scientific ideas of product design and use for such a long time has left deep imprints on today's practices of designing. Fallman (2007) calls $\mathrm{HCl}$ an "implicit design discipline", a discipline that works under the models of scientific research-based understandings of design, but under covers conducts designoriented work, which creates a conflict within the discipline. McCarthy and Wright (2004) go so far to say that $\mathrm{HCl}$ is not ready to deal with 'experience'.

Psychology attempts to explain user experience as a set of pragmatic ("do-goals" such as practical tasks) and hedonic needs ("be-goals", for example, the desire to be admired) in order to arrive at a tangible understanding of what to design for (Hassenzahl, 2004). Yet, critics have said that psychological accounts are reductionist (Wright et al., 2003), "that human experience is also constituted by continuous engagement with the world through acts of sense making at many levels" (p. 5) and that experience cannot be reduced to the user - object interaction alone. Hassenzahl, Diefenbach, and Göritz (2010), respond that it is however possible to categorise experiences according to sets of psychological needs such as autonomy, competence, relatedness, or influence - needs whose fulfilment, they say, triggers positive emotions (p. 361). This model, though, does not take into account the "situated, complex and dynamic" and "context" factors of experience, that some of the very same authors established as fundamental in an article four years earlier (see Hassenzahl \& Tractinsky, 2006).

Kuutti and Bannon (2014) speak of competing paradigms in $\mathrm{HCl}$ - the "interaction paradigm" and the "practice paradigm". The interaction paradigm, traditionally supported by cognitive psychology, honours the relationship between human and object, in contextremoved lab-settings. The practice paradigm is a new form of honouring the wider connections that make up social phenomena, and requires it to work with 'context', they say. Kuutti and Bannon (2014) identify an emerging interest in practice in $\mathrm{HCl}$, which they pin onto existing academic interests such as appropriation, research 'in the wild', materiality, and explicit mention of practice in sustainable $\mathrm{HCl}$. They say that this presents an opportunity for a new research agenda in $\mathrm{HCl}$. Opportunities for $\mathrm{HCl}$ are seen in pragmatic models of understanding technology design (Fisher, 1997; Wright et al., 2003). And amendments to existing methodological models are called for in the way of how ethnography is used in design (Button, 2000; Dourish, 2006). There is a sense of a new era in designing for technology. 
Sustainable technology design has already established ties with practice-oriented inquiry (Kuutti \& Bannon, 2014). An example of this is the work of Lenneke Kuijer, who has developed a framework for design, to take practices from the "unit of analysis" to the "unit of design" (Kuijer, 2014; Kuijer, De Jong, \& Van Eijk, 2013). She mostly draws on the sociological work done by a researcher team around Elizabeth Shove, who reason that social change needs to be conceptualised beyond conventional models of "attitude, behaviour, and choice" (Shove, 2010; Shove, Hand, \& Watson, 2012). In consumption studies of sociology, theories of practice build the conceptual basis for alternative understandings of use, where consumers engage in practices of "appropriation and appreciation" in a highly creative manner (Warde, 2005). Innovation is here seen as the active participation of consumers in everyday life (Shove et al., 2012; Shove, Watson, Hand, \& Ingram, 2007), in the form of an "active and ongoing integration of images, artefacts and forms of competence" (Shove \& Pantzar, 2005, p. 43). However, as Kuijer points out, this practice-oriented conceptualisation of how people participate through use and consumption is helpful for design analysis, but does leave designers' work in this process open for further investigation. Shove et al. (2007) themselves posed this challenge to designers when they remarked, "If everyone is a designer, to what special expertise does the profession lay claim?" (pp. 136-138).

What the practice paradigm means for those who are in the position of wanting change, and the designers who operate within this organisational premise, is left open for investigation. There is a large work force of professional designers, who are implicated in the social process of how things end up being. The need of reconceptualising change and innovation affects designers directly. "Product designers rarely determine what gets made, but their working methods embody and reproduce ideas and concepts that matter for the detail of material culture and for the practices of which it is part" (Shove et al., 2007, pp. 136-138). Not only are designers impacted as the supposed agents, subject to arising tensions between understandings of objectivist design knowledge production and experienced subjectivity, but they are also implicated in outcomes of change processes. In practice-oriented theories practitioners are part of sociomaterial configurations which organise activity (Gherardi, 2010, 2012; Orlikowski, 2007). The material is here as implicated in outcomes as human intention. It is hence not the individual intention of the designer which determines design outcomes. It does matter, for example, whether pen and paper are used for conveying ideas, or a prototyping software. It can be derived, however, that designers contribute in significant ways. Even the various understandings of design, which we have looked at critically in the review of paradigms, are "normative infrastructures" (Gherardi, 2012, p. 150) which are co-produced by the practitioners of the practice as a form of "practical accomplishment" (p. 135). Practitioners' doings and sayings help constitute practices, in the same time as they are constituted by the practices of which they are part (Schatzki, 1996, 2002). Designers engage in activities which are established within the processes of their professional work (Shove et al., 2007, pp. 136138). These activities may be very different to the activities of people who use the objects they help create, and yet, these activities affect wider outcomes. Designers engage with practices around users - they for example invite users for user testing, or draw up confidential spreadsheets of user research participants. They engage in practices of use representation - they for example employ drawing materials and software to create representations. They are entangled within sociomaterial environments made up of 
computers, managers, whiteboards, engineers, bean bags and foosball tables, or whatever. Designers participate in significant ways in the practices of product designing. Just in what ways is not clear.

This paper identifies a need to consider deeper the angle of design in practice-theoretical analysis, and in particular that of the designer, the putative agent in design. This leads directly to the work of Lucy Kimbell. She has suggested to view "design as a situated, local accomplishment" (Kimbell, 2012), through a framework of design-as-practice and designsin-practice, to acknowledge how design practitioners and design artefacts constitute practices. She criticises the ways how design thinking centres the designer, and the supposedly particular ways of doing, knowing and being as a professional designer, within the design process. "But perhaps more interestingly, we might attend to the material and discursive practices in which designers of particular kinds do, know, and say particular things and how they come to do, know, and say these things but not others. In so doing we might develop a richer understanding of professional design and its effects" (Kimbell, 2012, p. 130). In Kimbell's view, practice theory accounts for, first, distributed activity across people and artefacts, second, the constitution of structures in practice, third, the role of objects, and fourth, knowledge. She sees practice theory as an alternative which solves a number of current issues in the concept of design: Firstly, the dualism between thinking and knowing and acting, secondly, designer's diverse ways of doing, knowing and saying which are unaccounted for in prevailing design process models, and thirdly, that the designer is seen as a main agent (Kimbell, 2012, p. 141). Kimbell's work, the reconceptualization of design thinking, knowing and acting, as a social practice, is the beginning of creating this missing link in the emergent coalition between design and practice theory - and it is this particular crossover we suggest to further, from the particular angle of $\mathrm{HCl}$ and technology design. The focal point should be how designers in technology design participate in the practice of producing design knowledge - and how they are constituted in, and constitute, this process.

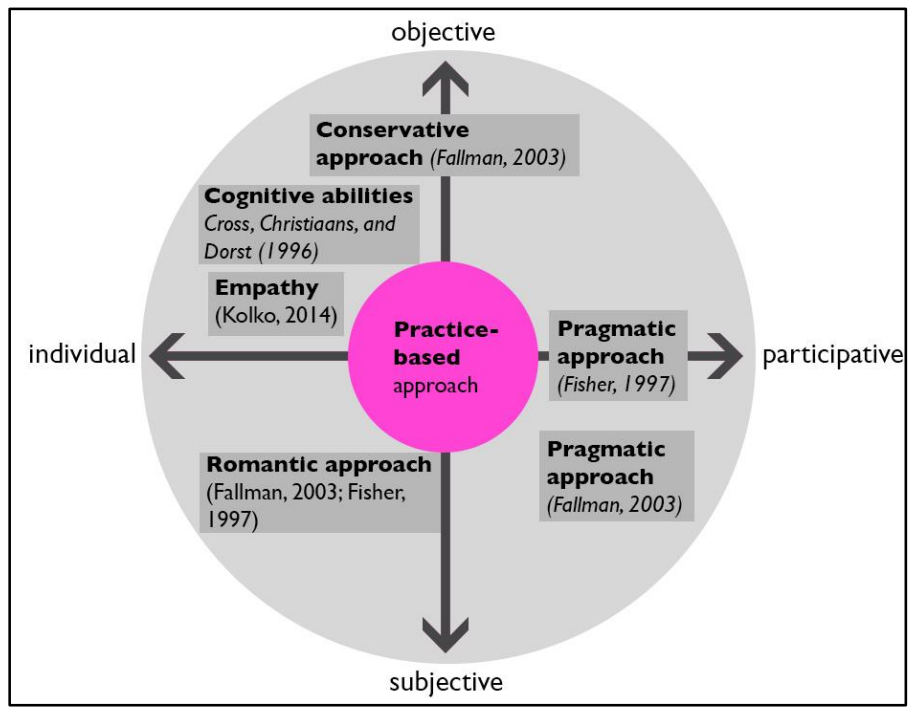

Figure 2 Practice-based paradigm 


\section{Conclusion}

We have tried to pull together conflicting ideas and concepts within design processes around technology, to highlight some of the tensions which do exist. In $\mathrm{HCl}$, objectivist understandings of knowledge have shown to bring tensions for both the design process as well as its practitioners (Button, 2000; Dourish, 2006; Suchman, 2002) as they are faced with their own subjectivity within the process (Fallman, 2003). In the same time, individualist concepts of agency do run counter to a pragmatist and practice-oriented appetite within design practices (Fisher, 1997; Kuutti \& Bannon, 2014; McCarthy \& Wright, 2004). The arising tensions are likely to affect, both, design processes as well as designers.

In consumption studies of sociology, some of these issues have already been reconciled, through a conceptualisation of users as creative participants in innovation (Shove et al., 2012; Shove \& Pantzar, 2005; Shove et al., 2007; Warde, 2005). This may aid organisations and designers to have a more helpful view on how their products and services fit into people's everyday lives. But while sustainable design research has begun to incorporate practice-oriented design frameworks (Kuijer, 2014; Schatzki, 2011; Shove, 2008), research on how professional designers are implicated in this social process of how products come to be, has been covered relatively little. Tentative conceptualisations of design-as-practice and designs-in-practice (Kimbell, 2011, 2012) have made some advance in this field. However, we propose to further the crossover of practice-oriented research and professional designing in the more technically oriented fields such as $\mathrm{HCl}$.

For designers, new conceptualizations of their work arise with practice theoretical ideas. Practice theoretical ideas of the social create the need of rethinking designers' own work practices, and the ways how designers constitute, and are constituted, within this social dynamic. Problematic expectations and tensions arise in designers' work, as we have seen in the review of the understandings of agency and knowledge in design. And it appears that designers are significantly affecting professional designing of consumer products. But it has also become clear that they are significantly affected within this practice, and that the material plays a role in this sociomaterial configuration of which designers are part. Following Gherardi (2006, 2012), new understandings of the social dynamic in which designers engage, may pose opportunities for designers to make individual choices about their engagement. In particular, if normative understandings form part of the practical accomplishments in which practitioners take part (Gherardi, 2012), this may allow a resolving of some of the issues and debates which designers in $\mathrm{HCl}$ currently face. Designers may be best supported by new conceptualisations of their work practices conceptualisations which help illustrate in what ways designers are affected, and in what ways they affect outcomes of design.

\section{References}

Beck, K., Beedle, M., A., V. B., Cockburn, A., Cunningham, W., Fowler, M., ... Kern, J. (Producer). (2001, 3rd March 2017). Manifesto for agile software development. Retrieved from http://www.agilemanifesto.org/

Button, G. (2000). The ethnographic tradition and design. Design Studies, 21(4), 319-332.

Caroll, J. M. (1997). HUMAN-COMPUTER INTERACTION: Psychology as a Science of Design. Annual Review of Psychology, 48(1), 61-83.

Cooper, A. (2004). The inmates are running the asylum: Why high-tech products drive us crazy and how to restore the sanity. Indianapolis, IN, USA: Sams. 
Cross, N. (1982). Designerly ways of knowing. Design Studies, 3(4), 221-227.

Cross, N., Christiaans, H., \& Dorst, K. (1996). Introduction: The Delft Protocols Workshop. In N. Cross, H. Christiaans, \& K. Dorst (Eds.), Analysing Design Activity (pp. 1-16). England: John Wiley \& Sons Ltd.

Dourish, P. (2006). Implications for Design. Paper presented at the CHI 2006, Montreal, Quebec, Canada.

Dreyfuss, H. (1955). Designing for People. New York: Simon and Schuster.

Fallman, D. (2003). Design-oriented Human-Computer Interaction. Paper presented at the CHI 2003, Ft. Lauderdale, Florida, USA.

Fallman, D. (2007). Why Research-Oriented Design Isn't Design-Oriented Research: On the Tensions Between Design and Research in an Implicit Design Discipline. Knowledge, Technology \& Policy, 20(3), 193-200.

Fisher, T. (1997). The Designer's Self-Identity - Myths of Creativity and the Management of Teams. Creativity and Information Management, 6(1), 10-18.

Flowers, E. (2012). UX is not UI | Experience Design at Hello Erik. Retrieved from http://www.helloerik.com/ux-is-not-ui

Fredheim, H. (2016). Why User Experience Cannot Be Designed - Smashing Magazine.

Garrett, J. J. (2011). The elements of user experience: user-centered design for the web (2nd. ed.). Berkeley, CA: New Riders.

Gedenryd, H. (1998). How designers work - making sense of authentic cognitive activities. (Ph.D. Thesis), University of Lund, Sweden.

Gherardi, S. (2006). Organizational knowledge: The texture of workplace learning. Oxford, UK: Blackwell Publishing.

Gherardi, S. (2010). Telemedicine: A practice-based approach to technology. human relations, 63(4), 501-524.

Gherardi, S. (2012). How to conduct a practice-based study: Problems and Methods. UK: Edward Elgar Publishing Limited.

Gothelf, J., \& Seiden, J. (2013). Lean UX: O'Reilly.

Hassenzahl, M. (2004). The Thing and I: Understanding the Relationship Between User and Product. In M. A. Blythe, K. Overbeeke, A. F. Monk, \& P. C. Wright (Eds.), Funology: From Usability to Enjoyment (Vol. 3, pp. 31-42). Dortrecht, The Netherlands: Kluwer.

Hassenzahl, M., Diefenbach, S., \& Göritz, A. (2010). Needs, affect, and interactive products - Facets of user experience. Interacting with Computers, 22(5), 353-362.

Hassenzahl, M., \& Tractinsky, N. (2006). User experience - a research agenda. Behaviour \& Information Technology, 25(2), 91-97.

Hysaalo, H. (2009). A Break from Novelty: Persistence and Effects of Structural Tensions in UserDesigner Relations. In A. Voss, M. Hartswood, R. Procter, M. Rouncefield, R. S. Slack, \& M. Buescher (Eds.), Configuring User-Designer Relations. London: Springer-Verlag.

Johnson, A. G. (2000). The Blackwell dictionary of sociology a user's guide to sociological language (2nd ed.. ed.). Oxford, OX, UK ; Malden, Mass., USA: Blackell Publishers.

Jones, J. C. (1963). A method of systematic design Conference on design methods. Oxford/New York: Pergamon Press.

Kimbell, L. (2011). Rethinking Design Thinking: Part I. Design and Culture, 3(3), 285-306. doi:10.2752/175470811x13071166525216

Kimbell, L. (2012). Rethinking Design Thinking: Part II. Design and Culture, 4(2), 129-148.

Knapp, J., Zeratsky, J., \& Kowitz, B. (2016). Sprint: How to Solve Big Problems and Test New Ideas in Just Five Days: Simon and Schuster.

Kolko, J. (2014). Well-designed: how to use empathy to create products people love. Boston, Massachusetts: Harvard Business Review Press.

Kuijer, L. (2014). Implications of Social Practice Theory for Sustainable Design. (Ph.D. Thesis), Technische Universiteit Delft. 
Kuijer, L., De Jong, A., \& Van Eijk, D. (2013). Practices as a unit of design: An exploration of theoretical guidelines in a study on bathing. ACM Transactions on Computer-Human Interaction (TOCHI), 20(4), 21.

Kuniavsky, M. (2003). Observing the user experience: A practitioner's guide to user research. San Francisco, California; London: Morgan Kaufmann.

Kuniavsky, M. (2007). User Experience and $\mathrm{HCl}$ The Human-Computer Interaction Handbook: Fundamentals, Evolving Technologies, and Emerging Applications (2 ed., pp. 897-915). New York: Lawrence Erlbaum Associates Inc.

Kuutti, K. (2001). Hunting for the lost user: From sources of errors to active actors - and beyond. Paper presented at the Cultural Usability Seminar, Media Lab, University of Art and Design, Helsinki.

Kuutti, K., \& Bannon, L. J. (2014). The turn to practice in HCl: towards a research agenda. Paper presented at the 32nd annual ACM conference on Human factors in computing systems.

Law, E., Roto, V., Hassenzahl, M., Vermeeren, A., \& Kort, J. (2009). Understanding, Scoping and Defining User eXperience: A Survey Approach. Paper presented at the CHI 2009, Boston, MA, USA.

Mackay, H., Carne, C., Beynon-Davies, P., \& Tudhope, D. (2000). Reconfiguring the User: Using Rapid Application Development. Social Studies of Science, 30(5), 737-757.

Maguire, M. (2001). Methods to support human-centred design. International Journal of HumanComputer Studies, 55(4), 587-634. doi:10.1006/ijhc.2001.0503

McCarthy, J., \& Wright, P. (2004). Technology as experience. London: The MIT Press.

Mueller, R., \& Thoring, K. (2012). Design Thinking vs. Lean Startup: A comparison of two user-driven innovation strategies. Paper presented at the International Design Management Research Conference, Boston.

Nielsen, J. (1994). Estimating the number of subjects needed for a thinking aloud test. International Journal of Human-Computer Studies, 41(3), 385-397.

Nielsen, J. (2000). Designing web usability: The practice of simplicity. Indianapolis, Ind.: New Riders Publishing.

NN group. (2016). Don Norman: The term "UX": Youtube.

Norman, D. (1988). The Design of Everyday Things. New York: Doubleday.

Norman, D., \& Nielsen, J. (2016). The Definition of User Experience (UX).

Olyslager, P. (2012, 2012-07-02). Why The User Experience Can Or Cannot Be Designed - Usabilla Blog. Retrieved from http://blog.usabilla.com/how-to-design-for-the-user-experience/

Orlikowski, W. J. (2007). Sociomaterial Practices: Exploring Technology at Work. Organization Studies, 28(9), 1435-1448.

Otto, T., \& Smith, R. C. (2013). Design anthropology: a distinct style of knowing. In W. Gunn, T. Otto, \& R. C. Smith (Eds.), Design Anthropology: Theory and Practice (pp. 1-29). New York, USA; London, UK: Bloomsbury Academic.

Patton, J. (2014). User Story Mapping: O'Reilly.

Ries, E. (2011). The Lean Startup. London: Portfolio Penguin.

Scapin, D. L., Senach, B., Trousse, B., \& Pallot, M. (2012). User Experience: Buzzword or New Paradigm?

Schatzki, T. R. (1996). Social Practices: A Wittgensteinian Approach to Human Activity and the Social. Cambridge: Cambridge University Press.

Schatzki, T. R. (2002). The site of the social: A philosophical exploration of the constitution of social life and change. State College: The Pennsylvania State University Press.

Schatzki, T. R. (2011). Where the Action is (On Large Social Phenomena Such as Sociotechnical Regimes) Sustainable Practices Research Group Working Paper 1. Manchester: University of Manchester. 
Schön, D. A. (1983). The reflective practitioner how professionals think in action. New York: Basic Books.

Shove, E. (Producer). (2008, 26th July 2016). Towards POPD. Towards Practice Oriented Product Design. Retrieved from http://www.lancs.ac.uk/fass/projects/dnc/index.html

Shove, E. (2010). Beyond the ABC: Climate Change Policy and Theories of Social Change. Environment and Planning A, 42(6), 1273-1285. doi:10.1068/a42282

Shove, E., Hand, M., \& Watson, M. (2012). The Dynamics of Social Practices: Everyday life and how it changes

Shove, E., \& Pantzar, M. (2005). Consumers, Producers and Practices: Understanding the invention and reinvention of Nordic walking. Journal of Consumer Culture, 5(1), 43-64.

Shove, E., Watson, M., Hand, M., \& Ingram, J. (2007). The Design of Everyday Life. Oxford: Berg.

Simon, H. A. (1996). The Sciences of the Artificial (3rd ed.). London, England: The MIT Press.

Suchman, L. (1994). Working Relations of Technology Production and Use. Computer Supported Cooperative Work (CSCW), 2, 21-39.

Suchman, L. (2002). Practice-Based Design of Information Systems: Notes from the Hyperdeveloped World. The Information Society, 18(2), 139-144. doi:10.1080/01972240290075066

Todish, T. R. (2013). UX Is Not A Verb | UX Magazine. UX Magazine. Retrieved from http://uxmag.com/articles/ux-is-not-a-verb

UX Mastery (Producer). (2012, October 6th, 2016). What the \#\$\%@ is UX Design? Retrieved from https://www.youtube.com/watch?v=Ovj4hFxko7c

Warde, A. (2005). Consumption and Theories of Practice. Journal of Consumer Culture, 5(2), 131153.

Woolgar, S. (1991). Configuring the user: the case of usability trials. In J. Law (Ed.), A sociology of monsters: essays on power, technology and domination. London: Routledge.

Wright, P., Blythe, M. A., \& McCarthy, J. (2006). User Experience and the Idea of Design in HCI. In S. W. Gilroy \& M. D. Harrison (Eds.), International Workshop on Design, Specification, and Verification of Interactive Systems (pp. 1-14). Berlin Heidelberg: Springer-Verlag.

Wright, P., McCarthy, J., \& Meekison, L. (2003). Making sense of experience. In M. A. Blythe, K. Overbeeke, A. F. Monk, \& P. Wright (Eds.), Funology: From Usablity to Enjoyment (pp. 43-53). Dortrecht, The Netherlands: Kluwer.

Young, I. (2015). Practical empathy for collaboration and creativity in your work. New York: Rosenfeld Media.

Zimmerman, J., Forlizzi, J., \& Evenson, S. (2007). Research through design as a method for interaction design research in $\mathrm{HCl}$. Paper presented at the SIGCHI conference on Human factors in computing systems, San Jose, CA, USA. 
About the Authors:

Ruth Neubauer is a PhD student in the Institute for Design Innovation at Loughborough University London. She is an experienced designer and focuses in her research on the social dynamic within design practices. She is interested in practice theory and sociomaterial aspects of practices.

Dr. Erik Bohemia is the Programme Director in the Institute for Design Innovation at Loughborough University London. He led to completion an AHRC funded project exploring how new digital technologies are affecting and changing knowledge translation in New Product Development and innovation. He is interested in Design as a cultural practice and the material effects of design.

Dr. Kerry Harman's main research interests are concerned with the politics of learning at work. Her work explores the interrelationships between workplace practices, knowledges, power and subjectivity. She uses the notions of embodiment and performativity to help in these explorations. Kerry is interested in developing ways of representing learning at work that enable different dimensions of workplace experience to become visible. She is also critical of the discourse of Mastery which prevails in much of the workplace learning literature. 